\title{
Degeneration of pyramidal cells of CA1, CA2, and CA3 area of the hippocampus in male rats under the influence of Simvastatin
}

Mohammad Saleh Ranaiy ( $\nabla$ st_ms.ranaiy@urmia.ac.ir)

Urmia University https://orcid.org/0000-0003-2342-2575

Farah Farokhi

Urmia University

Farrin Babaei-Balderlou

Urmia University

\section{Research Article}

Keywords: Cell degeneration, Cholesterol, Hippocampus, Simvastatin, Vitamin D

Posted Date: September 14th, 2021

DOl: https://doi.org/10.21203/rs.3.rs-898243/v1

License: (c) (i) This work is licensed under a Creative Commons Attribution 4.0 International License.

Read Full License 


\section{Abstract}

Background: Simvastatin is a lipophilic statin and can cross the blood-brain barrier. This study aimed to evaluate the Effect of Simvastatin on pyramidal cells in CA1, CA2, and CA3 regions of the hippocampus in healthy male rats. Method: For the experiment, 36 male Wistar rats with an average weight of 300-250 g were divided into six groups (each group comprised six heads). Groups: 1): Control group, 2): Vitamin D dose $5 \mu \mathrm{g} / \mathrm{kg}, 3$ ): Simvastatin group dose $1 \mathrm{mg} / \mathrm{kg}, 4$ ): Simvastatin group dose $10 \mathrm{mg} / \mathrm{kg}, 5$ ): Simvastatin group dose $1 \mathrm{mg} / \mathrm{kg}$ + vitamin D dose $5 \mu \mathrm{g} / \mathrm{kg}$, 6): Simvastatin group dose $10 \mathrm{mg} / \mathrm{kg}+$ vitamin D dose 5 $\mu \mathrm{g} / \mathrm{kg}$. The duration of drug use was 28 days. At the end of the drug administration period, the animals were slaughtered, then blood samples were taken from the animals (to check TC[1] and LDL-C[2]), and finally, the brain tissue of the animals was extracted to prepare microscopic sections. Results: Statistical results of total cholesterol and LDL-C in rat serum showed that the groups receiving simvastatin 10 $\mathrm{mg} / \mathrm{kg}$ and simvastatin $10 \mathrm{mg} / \mathrm{kg}$ with vitamin D supplement $5 \mu \mathrm{g} / \mathrm{kg}$ were significantly different compared to the control group $(\mathrm{P}<0.05)$.

Statistical results showed a significant increase $(P<0.05)$ in degenerated cells in the groups receiving simvastatin $10 \mathrm{mg} / \mathrm{kg}$ and simvastatin $10 \mathrm{mg} / \mathrm{kg}$ with vitamin D supplementation compared with the control group in CA1 and CA2 regions. The statistical results of the study of the percentage of The statistical results of the study of the rate of degenerative cells in CA3 area CA3 of the hippocampus showed that all groups except the vitamin $D$ group had a significant difference $(P<0.50)$ in the percentage of degenerative cells in this region compared to the control group.

Conclusion: The results of the present study showed that Simvastatin, due to its lipophilic nature, easily crosses the blood-brain barrier and reduces cholesterol in the brain, thus causing the degeneration of pyramidal cells in the hippocampus.

[1] Total cholesterol

[2] Low-Density Lipoproteins

\section{Background}

The first statin was discovered and isolated from microorganisms in 1972 by Dr. Akira Ando's research team [1]. Statins, the inhibitor of 3-hydroxy-3-methylglutaryl A (HMG-CoA), are known as plasma cholesterol-lowering drugs and are widely used in patients with blood cholesterol disorders. The primary function of statins is to lower cholesterol by competitively and reversibly inhibiting the enzyme HMG-COA reductase in the rate-limiting stage of cholesterol production. HMG-CoA combines Acetyl-CoA and Acetoacetyl-CoA, converted to mevalonate by HMG-CoA reductase and NADPH cofactors [2]. 
The liver mainly absorbs statins, and in the liver, inhibiting the enzyme (HMGCR), the primary enzyme involved in cholesterol synthesis, lowers serum cholesterol levels.[3] Statins inhibit HMG-CoA reductase in the liver by regulating hepatocyte LDL receptors, increasing circulating LDL-C clearance, and decreasing plasma LDL-cholesterol levels [4]. Simvastatin is a member of the lipophilic family of statins [5]. Lipophilic statins can cross the blood-brain barrier and, as a result, can affect most high-cholesterol organs such as the brain [6]. Following chronic use of statins, a decrease in 24S-hydroxycholesterol levels in plasma and cerebrospinal fluid (CSF) has been observed, which is parallel to the reduction in cholesterol in the brain of long-term treatment with statins. Statins simultaneously affect the concentration of cholesterol in the brain [7] [3].

Statins, like other drugs, have side effects that; one of the main obstacles to statin therapy is the lack of resistance to muscle myopathy caused by statins.[8] Some studies show that Simvastatin has protective effects on the nervous system [9] [10]. Still, there are other reports of the adverse effects of Simvastatin on dose-dependent and time-dependent nerve system cells [11].[12] The hippocampus is part of the limbic system, which is in the middle temporal lobe of the brain and is involved in memory and learning. [13] Lipophilic drugs such as Simvastatin can cross the blood-brain barrier and affect brain cholesterol [14]; as a result, they can cause changes in the hippocampal tissue. Tens of millions of patients worldwide are currently receiving statins to treat hypercholesterolemia [15]. Because of the importance of statins, in the present study, the Effect of Simvastatin at $1 \mathrm{mg} / \mathrm{kg}$ and $10 \mathrm{mg} / \mathrm{kg}$ for 28 days on rat hippocampal tissue Healthy and without brain damage were evaluated. It should be noted that the use of vitamin D supplements in some groups was done because, in some cases, vitamin D is used as a supplement with statins [16].

\section{Materials And Methods}

Thirty-six male Westar rats weighing 250-300g were purchased from the animal house of Urmia University. All procedures were followed according to the National Institute of Health guide for the care and use of Laboratory Animals (NIH Publications No. 8023, revised 1978) and local guidelines for compassionate use of animals in research; Rats were kept in cages with open access to standard tap water and compact chow. The animals were held in the same laboratory conditions $\left(18^{\circ} \mathrm{C}\right.$ to $23^{\circ} \mathrm{C}$ room temperature and controlled humidity) with alternating 12-h light and dark cycles. The Ethics Committee has approved the proposal of this study of Urmia University (Ethics Code: IR-UU-AEC-3/1033 / DA).

\section{Animal grouping}

1. Healthy control group who received normal water and food and were not injected (C).

2. Vitamin D group who received only vitamin $D$ at a dose of $5 \mu \mathrm{g} / \mathrm{kg}$ (200 IU) [17] by intraperitoneal injection (VD).

3. Simvastatin group with a dose of $1 \mathrm{mg} / \mathrm{kg}$ [18] received a low dose of Simvastatin orally (SimL). 
4. Simvastatin group with a dose of $10 \mathrm{mg} / \mathrm{kg}$ [19] received high doses of Simvastatin orally daily $(\mathrm{SimH})$.

5. Simvastatin group with a low dose of $1 \mathrm{mg} / \mathrm{kg}$ with vitamin D supplement $5 \mu \mathrm{g} / \mathrm{kg}(\operatorname{SimL}+\mathrm{VD})$.

6. Simvastatin group with a high dose of $10 \mathrm{mg} / \mathrm{kg}$ with vitamin D supplement VD $5 \mu \mathrm{g} / \mathrm{kg}(\mathrm{SimH}+\mathrm{VD})$.

The drugs were administered once daily for 28 days.

The drug simvastatin used in the present study was produced by Timova Pharmaceutical Company (Denmark).

\section{Blood sampling}

At the end of 28 days of treatment, the animals were anesthetized with ether and sacrificed after the blood collection phase. After one hour, all blood samples were centrifuged at $1500 \mathrm{rpm}$ for 10 minutes to isolate their serum. The obtained serum was carefully separated by a sampler and stored in Ependrov microtubes in a freezer at $-70^{\circ} \mathrm{C}$ until biochemical tests were performed. Serum levels of Cholesterol Total and LDL-C were measured by spectrophotometry (enzymatic colorimetry) and using special measuring kits (Pars Azmoun Company).

\section{Tissue study method}

The brains of mice were transferred to $10 \%$ formalin for fixation and then subjected to dehydration, clarification, paraffin, and molding, then six micron-thick sections were prepared by microtome. After staining with hematoxylin and eosin, they were examined and photographed with a light microscope. The hippocampus was explicitly studied.

For cell counting under a light microscope with $x 400$ magnification and with the help of an Eyepiece micrometer grid, it was counted in a square with an area of 100 micrometers (Nikon, DXM 120 USA). Degeneration of neurons (degeneration: abnormal changes in cell appearance including cell shrinkage, membrane uniformity, cytoplasm density) were examined by light microscopy [20].

Cell counts in the hippocampus were performed separately in three regions: CA1, CA2, CA3.

\section{Statistical analysis}

Data were analyzed using SPSS19 software using one-way analysis of variance and Tukey test. The results were presented as mean \pm standard error. $\mathrm{P}<0.05$ was considered as a significant level.

\section{Results}

\section{Results for serum LDL-C}


Statistical results of serum LDL-C showed that rats $(\mathrm{SimH})$ and (SimH + VD) had a significant difference in reducing LDL-C compared to the control group $(P<0.05)$, but other The groups did not show any significant differences compared to the control group $(P>0.05)$ (Diagram 1$)$.

\section{Results for serum TC}

Statistical results of total serum cholesterol showed that the SimH and SimH + VD groups had a significant decrease in total cholesterol compared to the control group $(P<0.05)$, but other groups showed no significant difference They did not deliver to the control group ( $P>0.05)$ (Diagram 2).

\section{Results on the percentage of degenerative cells in the CA1 region of the hippocampus}

The study's statistical results of the percentage of degenerative cells in the CA1 region (pyramidal neurons) of the rat hippocampus showed that SimH and the SimH + VD group significantly increased the percentage of degenerative cells in this region compared to the control group. $(P<0.05)$ but other groups did not differ significantly from the control group $(P>0.05)$ (Diagram 3$)$.

\section{Results on the percentage of degenerative cells in the CA2 region of the hippocampus}

The study's statistical results of the percentage of degenerative cells in the CA2 region (pyramidal neurons) of the rat hippocampus showed that SimH and the SimH + VD group significantly increased the percentage of degenerative cells in this region compared to the control group $(P<0.05)$ but other groups did not differ significantly from the control group $(P>0.05)$ (Diagram 4).

\section{Results on the percentage of degenerative cells in the CA3 region of the hippocampus}

The study's statistical results of the percentage of degenerative cells in the CA3 region (pyramidal neurons) of the rat hippocampus showed that, except for the VD group, other groups had a significant difference in the percentage of degenerative cells in this region compared to the group. Are controls ( $P$ $<0.05$ ), (Diagram 5).

\section{Discussion}

Statins are valuable drugs in the treatment of atherosclerotic cardiovascular disease. This family of drugs reduces mortality from these diseases in primary (Patients with no clinical evidence of coronary heart disease) and secondary prevention (Patients with specific coronary heart disease), even if serum cholesterol levels are normal. Independent studies in patients with heart failure that have been associated with LDL-C levels have reported beneficial effects of statin administration [21, 22]. Statins have an impact on serum cholesterol concentration [23]. Controlled trials have shown that drug treatments with statins reduce LDL-C levels and reduce the risk of cardiovascular disease [24-27].

All statins competitively bind to the catalytic domain of HMG-COA reductase. This family of drugs prevents HMG-CoA from reaching the active site of the LDL-C receptor. As a result, it enhances the 
reabsorption of LDL-C and LDL-C precursors from the systemic circulation. Proteins that bind to the sterol regulatory unit (SREBP) sense changes in cholesterol levels and subsequently increase the expression of LDL-C receptors to reabsorb LDL-C from serum to compensate for the decrease in cellular cholesterol; as a result, a significant proportion of cholesterol-lowering statins, indirectly clear LDL-C from plasma [28]. Simvastatin treatment reduced serum cholesterol levels [29].

Simvastatin is inactive as a prodrug and is converted to active beta-hydroxy derivatives in the gastrointestinal tract. The most significant effect of this drug is on the liver. This preferential effect can be attributed to differences in different tissues in removing the drug from the blood. Plasma triglycerides decrease, and HDL-C levels increase during treatment with this drug. The HMG-COA inhibitor is effective in patients with elevated plasma LDL levels [30-34]. The results of the present study, which was performed on male rats for 28 days, showed a significant decrease in serum LDL-C levels in the SimH group and the SimH + VD group and a significant reduction in serum TC levels in the SimH group and the $\mathrm{SimH}$ group + VD in male rats (Diagrams 1 and 2). These results indicate the positive Effect of Simvastatin on cholesterol reduction [35]. However, other groups did not show any significant effect on these two factors compared to the healthy control group, and this lack of effect is due to the low dose of Sim $1 \mathrm{mg} / \mathrm{kg}$, which is a low dose.

Cholesterol is an essential biological molecule in all cells and cell membranes and in the blood that includes many functions, including myelin sheath formation, expression of neurotransmitter receptors, neuronal synapses, production of steroid hormones (e.g., testosterone, estrogen, etc.). Cortisol and vitamin D) are involved in signaling the central and peripheral nervous systems, as well as in healthy cell function and the transport of antioxidants such as vitamin E, carotenoids, and coenzyme Q 10 Important for energy production, cellular function, and defense of the body against free radicals [36]. Lipophilic statins such as Simvastatin can cross the blood-brain barrier and, as a result, can affect most highcholesterol organs such as the brain [6]. Studies have shown that high doses of Simvastatin $(100 \mathrm{mg} / \mathrm{kg})$ affect brain cholesterol synthesis, most likely due to the drug passing directly through the blood-brain barrier, lipophilic, and locally inhibiting cholesterol synthesis in the brain. It seems that the ability of different statins to inhibit cholesterol synthesis in the CNS depends on their lipophilicity and distribution in the brain. The use of lipophilic statins such as Simvastatin in high doses may affect the cholesterol synthesis of the brain in humans [14].

The study results of Ajaib S. Paintlia and Manjeet K. Paintlia et al. showed no side effects of different statins on the expression of proteins directly involved in cholesterol synthesis. However, cholesterol levels in the cerebral cortex decreased slightly during the experiment [37]. Given the vital role of cholesterol in the CNS, altering its metabolism can have devastating consequences in humans [38]. In addition, research has shown that HMGR activity is low in the brainstem, while higher activity is observed in the hippocampus, cortex, and cerebellum [39]. In the present study, the effects of Simvastatin at doses of 1 $\mathrm{mg} / \mathrm{kg}$ and $10 \mathrm{mg} / \mathrm{kg}$ orally over 28 years on healthy adult male rats were evaluated for the Effect of Simvastatin on hippocampal tissue. Although the level of cerebral cholesterol was not specifically studied in the present study, the study results of serum profiles showed that Simvastatin at a dose of 10 
$\mathrm{mg} / \mathrm{kg}$ causes a significant reduction in LDL-C and total serum cholesterol (Diagrams 1 and 2). In this regard, in the present study, the results of the examination of hippocampal tissue in male rats that received the drugs for 28 days showed that the pyramidal cells of CA1 regions in the SimH group (Fig. 4B) and SimH + VD group (Fig. 6-B) have degenerated and the staining of these cells during passage Tissue enhanced (Diagram 3).

Interestingly, vitamin D supplementation in the CA1 group in the SimH + VD group reduces the percentage of degenerate cells compared to the SimH group, which indicates the positive effect of vitamin $D$ supplementation in reducing the negative Effect of Simvastatin. However, This significant positive Effect was not observed in CA2 and CA3 regions (Fig. 4, 6-C, D). The statistical results of the study of pyramidal cells in the CA2 area showed a significant percentage of degenerate cells in the SimH (Fig. 4-C) and $\mathrm{SimH}+\mathrm{VD}$ groups (Fig. 6-C) compared to the control group and other groups (Diagrams 4). However, in the groups receiving SimL, SimL $+V D$, and VD, no significant effect was observed on the degenerate of cells in the CA2 region compared to the control group. The statistical results of the study of pyramidal cells in the CA3 region show a significant percentage of degenerate cells in the groups receiving SimH (Fig. 4-D), SimH + VD (Fig. 6-D), SimL (Fig. 3-D) and, SimL + VD (Fig. 5-D) compared to the control group (Diagrams 5).

The results of degenerative pyramid cell studies in CA1, CA2, and CA3 regions may seem very strange. Perhaps this difference in outcomes in these hippocampal regions is due to the physiological and biochemical differences of cells in the different areas of the hippocampus. Despite the significant Effect of Simvastatin on cell destruction in all three hippocampal regions at a dose of $10 \mathrm{mg} / \mathrm{kg}$, Simvastatin at a dose of $1 \mathrm{mg} / \mathrm{kg}$ showed only a significant adverse effect on cells in the CA3 region. Measures that directly study cerebral structure, cerebral blood flow, cholesterol circulation, and neuronal activity can be used to understand how statins affect the CNS. Still, there are few studies in this area, and their results are different. Decreased hippocampal volume along with memory impairment has been studied in some age-related studies. However, there are few studies on the effect of statins on the hippocampus, and there are many differences in their results.[40,41] Previous and current research on the effect of statin drugs has shown a significant effect of Simvastatin on the hippocampus [39].

Simvastatin-induced toxicity has been reported on different cell types.[11] Simvastatin interferes with myelin repair in myelinated mice.[42] The research results by Kamminskey et al. Showed that the treatment of astrocytes with Simvastatin induced apoptosis in cells depending on dose and time [11]. Statins lower cholesterol [43], and because cholesterol is an integral part of animal cell membranes, any drug that affects cholesterol levels can affect animal cell membrane cholesterol. Because statins are cholesterol-lowering drugs, they can affect cell membranes. Cholesterol does not cross the blood-brain barrier, and brain cholesterol is produced by its production in this organ [44]. Any interference with the concentration of cholesterol in the brain can affect the cell wall. As a result of the effect of statins on cholesterol and increase in cell membrane permeability, the cholesterol balance of the cell wall is disturbed. In preparing tissue sections for microscopic studies, the dye can enter the cell and affect the results of the studies. Cells in different areas of the hippocampus are no exception. Each region of the 
hippocampus has cells with different functions from other areas of the hippocampus, and the cells in each region have different cellular characteristics and even various afferents and efferents of other regions [45] [46] [47].

Some studies of the adverse effects of statins include cessation of DNA synthesis [48] and proliferation cell death in primary neuronal cell culture [12,49], end of neuroblasts [50], loss of synapses [51], and negative impact on cognitive function in clinical trials.[52] The results of Beitan et al.'s study to evaluate the effect of statins on memory showed contradictory results so that the use of Simvastatin for four weeks at a dose of $10 \mathrm{mg} / \mathrm{kg}$ per day caused memory impairment in the Barnes maze test; this effect was not observed in rats that took Simvastatin at a dose of $30 \mathrm{mg} / \mathrm{kg} /$ day[19]. The results of the present study, which was performed to evaluate the effect of oral administration of Simvastatin for four weeks on healthy mice, show a significant negative effect of Simvastatin on pyramidal cells of CA1, CA2 and CA3 regions of the hippocampus at a dose of $10 \mathrm{mg} / \mathrm{kg}$ simvastatin. This result obtained in the present study confirms the negative effect of $10 \mathrm{mg} / \mathrm{kg}$ simvastatin in the research of Beitan et al. [19]. It should be noted that the hippocampus is one of the main components in the memory process [13]. In this regard, the results of Zongmin and Steven (Zhongmin Xiang, Steven A. Reeves) research to investigate the Effect of Simvastatin on the progression of myelination in a mouse cerebellum cell culture model, indicating inhibition of cholesterol synthesis by Simvastatin during the progression of primary cells to neurons And showed oligodendrocytes and harmful effects of Simvastatin on myelination [53]. Simvastatin may affect oligodendrocyte cell survival signaling by blocking isoprenylation [50]. Simvastatin interferes with myelin repair by inhibiting lipid-associated signaling and cholesterol-dependent processes [54].

The findings of Sierra et al. To evaluate statins as neuroprotectants showed the preventive properties of statins as an effective strategy in protecting the brain against stroke.

After careful study of parameters such as potential access to the brain, the ability to lower cholesterol in neurons with appropriate immune profiles, and the ability to prevent nerve cell death from related mechanisms, the researchers said that Simvastatin was the best statin for Used in the prevention of neurogenic diseases [55]. The results of some studies suggest that Simvastatin was effective in inhibiting hippocampal cell apoptosis and inflammation in mice with Alzheimer's disease and that Simvastatin had protective effects on the nervous system $[9,56]$.

Research shows that treatment with Simvastatin has potent inhibitory effects on hippocampal nerve apoptosis, thus helping to improve memory $[57,58]$. Sun, $J$.; Et al., In a study to investigate Simvastatin in the hippocampus, reported that treatment with Simvastatin significantly reduced nerve damage and reduced apoptosis in the hippocampus [59]. However, the present study results showed that the Effect of Simvastatin on the hippocampal tissue of healthy male rats was inconsistent with the positive effects of Simvastatin on the hippocampal tissue mentioned above.

\section{Conclusion}


The present study results showed that Simvastatin, due to its lipophilic nature, readily crosses the bloodbrain barrier and reduces cholesterol in the brain, thus causing the degeneration of pyramidal cells in the hippocampus.

\section{Declarations}

Statins are at the forefront of the fight against atherosclerosis, as they effectively lower LDL-C, so their pleiotropic effects show the valuable role of statins in preventing cardiovascular disease [60]. Due to Simvastatin adverse Effects on Simvastatin in the present study and other harmful effects on the nervous system and other organs of the body [11], it is necessary to conduct more detailed research on this drug in the future physicians should prescribe Simvastatin with caution.

\section{Authors' Contributions}

All authors read and approved the final manuscript.

\section{-Ethical Approval and Consent to participate}

This article is extracted from the dissertation of Mohammad Saleh Ranaiy, and all authors are satisfied with their participation. The Ethics Committee has approved the proposal of this study of Urmia University (Ethics Code: IR-UU-AEC-3/1033 / DA).

\section{-Consent for publication}

All authors are delighted with the publication of this article.

\section{-Availability of supporting data}

There is data to support this article.

\section{-Competing interests}

There is no authors' conflict of interest.

\section{-Funding}

Urmia University was the sponsor of this article.

\section{-Authors' contributions}

All authors have contributed to this article.

\section{-Acknowledgements}

This article is taken from the dissertation of Mohammad Saleh Ranaiy. We thank the Department of Development and Physiology of Urmia University for providing the basics of this research. 


\section{-Authors' information}

Mohammad Saleh Ranaei (MSc), E-Mail: st_ms.ranaiy@urmia.ac.ir, Department of Biology, Faculty of Sciences, Urmia University, Urmia, Iran

Farah Farokhi ${ }^{1}$ (Ph.D.), E-Mail: f.farokhi@urmia.ac.ir, Department of Biology, Faculty of Sciences, Urmia University, Urmia, Iran

Farrin Babaei-Balderlou (Ph.D.), E-Mail: f.babaei@urmia.ac.ir, Department of Biology, Faculty of Sciences, Urmia University, Urmia, Iran

\section{Abbreviations}

TC

Total cholesterol

LDL-C

Low-Density Lipoproteins

HDL-C

High-Density Lipoproteins

HMGCR

Hydroxy Methyl Glutaryl CoA-reductase

VD

Vitamin D

Sim

Simvastatin

SimL

Low dose of Simvastatin $(1 \mathrm{mg} / \mathrm{Kg})$

$\mathrm{SimH}$

High doses of Simvastatin $(10 \mathrm{mg} / \mathrm{Kg})$

$\mu \mathrm{g}$

Micrograms

$\mathrm{mg}$

Milligram

$\mathrm{kg}$

Kilogram

\section{References}

1. Shinohara, M., et al., Possible modification of Alzheimer's disease by statins in midlife: interactions with genetic and non-genetic risk factors. Frontiers in aging neuroscience, 2014. 6: p. 71. 
2. Wood, W.G., W.E. Müller, and G.P. Eckert, Statins and neuroprotection: basic pharmacology needed. Molecular neurobiology, 2014. 50(1): p. 214-220.

3. Sharpe, L.J. and A.J. Brown, Controlling cholesterol synthesis beyond 3-hydroxy-3-methylglutaryl-CoA reductase (HMGCR). Journal of Biological Chemistry, 2013. 288(26): p. 18707-18715.

4. Daneschvar, H.L., M.D. Aronson, and G.W. Smetana, Do statins prevent Alzheimer's disease? A narrative review. European journal of internal medicine, 2015. 26(9): p. 666-669.

5. Farooqui, A.A., et al., Comparison of biochemical effects of statins and fish oil in brain: the battle of the titans. Brain research reviews, 2007. 56(2): p. 443-471.

6. van der Most, P.J., et al., Statins: mechanisms of neuroprotection. Progress in neurobiology, 2009. 88(1): p. 64-75.

7. McFarland, A.J., et al., Molecular mechanisms underlying the effects of statins in the central nervous system. International journal of molecular sciences, 2014. 15(11): p. 20607-20637.

8. Irwin, J., et al., The Effect of Lipophilicity and Dose on the Frequency of Statin-Associated Muscle Symptoms: A Systematic Review and Meta-Analysis of Randomised Controlled Trials. Heart, Lung and Circulation, 2017. 26: p. S302.

9. Rossoni, L.V., et al., Acute Simvastatin increases endothelial nitric oxide synthase phosphorylation via AMP-activated protein kinase and reduces contractility of isolated rat mesenteric resistance arteries. Clinical Science, 2011. 121(10): p. 449-458.

10. Wu, H., et al., Simvastatin-mediated upregulation of VEGF and BDNF, activation of the PI3K/AKt pathway, and increase of neurogenesis are associated with therapeutic improvement after traumatic brain injury. Journal of neurotrauma, 2008. 25(2): p. 130-139.

11. Kaminsky, Y.G. and E.A. Kosenko, Molecular mechanisms of toxicity of Simvastatin, widely used cholesterol-lowering drug. A review. Central European journal of medicine, 2010. 5(3): p. 269-279.

12. März, P., U. Otten, and A.R. Miserez, Statins induce differentiation and cell death in neurons and astroglia. Glia, 2007. 55(1): p. 1-12.

13. Squire, L.R., Memory and the hippocampus: a synthesis from findings with rats, monkeys, and humans. Psychological review, 1992. 99(2): p. 195.

14. Thelen, K.M., et al., Brain cholesterol synthesis in mice is affected by a high dose of Simvastatin but not pravastatin. Journal of Pharmacology and Experimental Therapeutics, 2006. 316(3): p. 11461152.

15. Mitka, M., Expanding statin use to help more at-risk patients is causing financial heartburn. Jama, 2003. 290(17): p. 2243-2245.

16. Anagnostis, P., et al., Comparative Effect of atorvastatin and rosuvastatin on 25-hydroxy-vitamin D levels in non-diabetic patients with dyslipidaemia: a prospective randomized open-label pilot study. The open cardiovascular medicine journal, 2014. 8: p. 55.

17. Dawson-Hughes, B., et al., effect of calcium and vitamin D supplementation on bone density in men and women 65 years of age or older. New England Journal of Medicine, 1997. 337(10): p. 670-676. 
18. Cui, X., et al., Chemokine, vascular and therapeutic effects of combination Simvastatin and BMSC treatment of stroke. Neurobiology of disease, 2009. 36(1): p. 35-41.

19. Baytan, S.H., et al., Simvastatin impairs spatial memory in rats at a specific dose level. The Tohoku journal of experimental medicine, 2008. 214(4): p. 341-349.

20. Azad, N., et al., Neuroprotective effects of carnosic acid in an experimental model of Alzheimer's disease in rats. Cell Journal (Yakhteh), 2011. 13(1): p. 39.

21. Deedwania, P.C. and U. Javed, Statins in heart failure. Cardiology clinics, 2008. 26(4): p. 573-587.

22. Foody, J.M., et al., Statins and mortality among elderly patients hospitalized with heart failure. Circulation, 2006. 113(8): p. 1086-92.

23. Pignone, M., C. Phillips, and C. Mulrow, Use of lipid lowering drugs for primary prevention of coronary heart disease: meta-analysis of randomised trials. Bmj, 2000. 321(7267): p. 983.

24. Lewis, S.J., et al., effect of pravastatin on cardiovascular events in older patients with myocardial infarction and cholesterol levels in the average range: results of the Cholesterol and Recurrent Events (CARE) trial. Annals of internal medicine, 1998. 129(9): p. 681-689.

25. Group, S.S.S.S., Randomised trial of cholesterol lowering in 4444 patients with coronary heart disease: the Scandinavian Simvastatin Survival Study (4S). The Lancet, 1994. 344(8934): p. 13831389.

26. Nissen, S.E., et al., Effect of intensive compared with moderate lipid-lowering therapy on progression of coronary atherosclerosis: a randomized controlled trial. Jama, 2004. 291(9): p. 1071-1080.

27. Sever, P.S., et al., Prevention of coronary and stroke events with atorvastatin in hypertensive patients who have average or lower-than-average cholesterol concentrations, in the Anglo-Scandinavian Cardiac Outcomes Trial-Lipid Lowering Arm (ASCOT-LLA): a multicentre randomised controlled trial. The Lancet, 2003. 361(9364): p. 1149-1158.

28. Trentman, T.L., S.G. Avey, and H. Ramakrishna, Current and emerging treatments for hypercholesterolemia: A focus on statins and proprotein convertase subtilisin/kexin Type 9 inhibitors for perioperative clinicians. Journal of anaesthesiology, clinical pharmacology, 2016. 32(4): p. 440.

29. Sparrow, C.P., et al., Simvastatin has anti-inflammatory and antiatherosclerotic activities independent of plasma cholesterol lowering. Arteriosclerosis, thrombosis, and vascular biology, 2001. 21(1): p. 115-121.

30. Bayorh, M.A., et al., Simvastatin and losartan enhance nitric oxide and reduce oxidative stress in saltinduced hypertension. American journal of hypertension, 2005. 18(11): p. 1496-1502.

31. Inman, S.R., et al., Simvastatin and L-arginine preserve renal function after ischemia/reperfusion injury. The American journal of the medical sciences, 2005. 329(1): p. 13-17.

32. İşeri, S., et al., Simvastatin attenuates cisplatin-induced kidney and liver damage in rats. Toxicology, 2007. 230(2-3): p. 256-264.

33. Rugale, C., et al., Simvastatin reverses target organ damage and oxidative stress in Angiotensin II hypertension: comparison with apocynin, tempol, and hydralazine. Journal of cardiovascular 
pharmacology, 2007. 50(3): p. 293-298.

34. Mauro Vieira Jr, J., et al., Simvastatin attenuates renal inflammation, tubular transdifferentiation and interstitial fibrosis in rats with unilateral ureteral obstruction. Nephrology Dialysis Transplantation, 2005. 20(8): p. 1582-1591.

35. Zhou, Q. and J.K. Liao, Statins and cardiovascular diseases: from cholesterol lowering to pleiotropy. Current pharmaceutical design, 2009. 15(5): p. 467-478.

36. Golomb, B.A., et al., Conceptual foundations of the UCSD Statin Study: a randomized controlled trial assessing the impact of statins on cognition, behavior, and biochemistry. Archives of internal medicine, 2004. 164(2): p. 153-162.

37. Paintlia, A.S., et al., HMG-CoA reductase inhibitor augments survival and differentiation of oligodendrocyte progenitors in animal model of multiple sclerosis. The FASEB journal, 2005. 19(11): p. 1407-1421.

38. Segatto, M., et al., Simvastatin treatment highlights a new role for the isoprenoid/cholesterol biosynthetic pathway in the modulation of emotional reactivity and cognitive performance in rats. Neuropsychopharmacology, 2014. 39(4): p. 841.

39. Segatto, M., et al., Regulation of cholesterol biosynthetic pathway in different regions of the rat central nervous system. Acta Physiologica, 2012. 206(1): p. 62-71.

40. Doraiswamy, P.M., D.C. Steffens, and D.R. Mcquoid, Statin use and hippocampal volumes in elderly subjects at risk for Alzheimer's disease: a pilot observational study. American Journal of Alzheimer's Disease \& Other Dementias ${ }^{\circledR}, 2004$. 19(5): p. 275-278.

41. Sparks, D.L., et al., Hippocampal volume change in the Alzheimer disease Cholesterol-Lowering Treatment trial. Cleveland Clinic journal of medicine, 2008. 75: p. S87-93.

42. Miron, V.E., et al., Statin therapy inhibits remyelination in the central nervous system. The American journal of pathology, 2009. 174(5): p. 1880-1890.

43. Athyros, V.G., et al., Pleiotropic effects of statins-clinical evidence. Current pharmaceutical design, 2009. 15(5): p. 479-489.

44. Schreurs, B.G., The effects of cholesterol on learning and memory. Neuroscience \& Biobehavioral Reviews, 2010. 34(8): p. 1366-1379.

45. Stark, C.E., P.J. Bayley, and L.R. Squire, Recognition memory for single items and for associations is similarly impaired following damage to the hippocampal region. Learning \& Memory, 2002. 9(5): p. 238-242.

46. Yukie, M., Connections between the amygdala and auditory cortical areas in the macaque monkey. Neuroscience research, 2002. 42(3): p. 219-229.

47. Givens, B.S. and D.S. Olton, Cholinergic and GABAergic modulation of medial septal area: Effect on working memory. Behavioral neuroscience, 1990. 104(6): p. 849.

48. Langan, T.J. and J.J. Volpe, Obligatory relationship between the sterol biosynthetic pathway and DNA synthesis and cellular proliferation in glial primary cultures. Journal of neurochemistry, 1986. 
46(4): p. $1283-1291$.

49. Michikawa, M. and K. Yanagisawa, Inhibition of cholesterol production but not of nonsterol isoprenoid products induces neuronal cell death. Journal of neurochemistry, 1999. 72(6): p. 22782285.

50. García-Román, N., et al., Lovastatin induces apoptosis of spontaneously immortalized rat brain neuroblasts: involvement of nonsterol isoprenoid biosynthesis inhibition. Molecular and Cellular Neuroscience, 2001. 17(2): p. 329-341.

51. Mauch, D.H., et al., CNS synaptogenesis promoted by glia-derived cholesterol. Science, 2001. 294(5545): p. 1354-1357.

52. Padala, K.P., P.R. Padala, and J.F. Potter, Simvastatin-induced decline in cognition. Annals of Pharmacotherapy, 2006. 40(10): p. 1880-1883.

53. Xiang, Z. and S.A. Reeves, Simvastatin induces cell death in a mouse cerebellar slice culture (CSC) model of developmental myelination. Experimental neurology, 2009. 215(1): p. 41-47.

54. Decker, L., Lipid rafts and integrin activation regulate oligodendrocyte survival. Journal of Neuroscience, 2004. 24(15): p. 3816-3825.

55. Sierra, S., et al., Statins as neuroprotectants: a comparative in vitro study of lipophilicity, blood-brainbarrier penetration, lowering of brain cholesterol, and decrease of neuron cell death. Journal of Alzheimer's Disease, 2011. 23(2): p. 307-318.

56. Endres, M., et al., Stroke protection by 3-hydroxy-3-methylglutaryl (HMG)-CoA reductase inhibitors mediated by endothelial nitric oxide synthase. Proceedings of the National Academy of Sciences, 1998. 95(15): p. 8880-8885.

57. Ramos, M.C., et al., Simvastatin modulates the Alzheimer's disease-related gene seladin-1. Journal of Alzheimer's Disease, 2012. 28(2): p. 297-301.

58. Hu, X., et al., Simvastatin inhibits the apoptosis of hippocampal cells in a mouse model of Alzheimer's disease. Experimental and therapeutic medicine, 2018. 15(2): p. 1795-1802.

59. Sun, J., et al., The effects of Simvastatin on hippocampal caspase-3 and Bcl-2 expression following kainate-induced seizures in rats. International journal of molecular medicine, 2012. 30(4): p. 739746.

60. Lloyd-Jones, D.M., et al., 2016 ACC expert consensus decision pathway on the role of non-statin therapies for LDL-cholesterol lowering in the management of atherosclerotic cardiovascular disease risk: a report of the American College of Cardiology Task Force on Clinical Expert Consensus Documents. Journal of the American College of Cardiology, 2016. 68(1): p. 92-125.

\section{Figures}



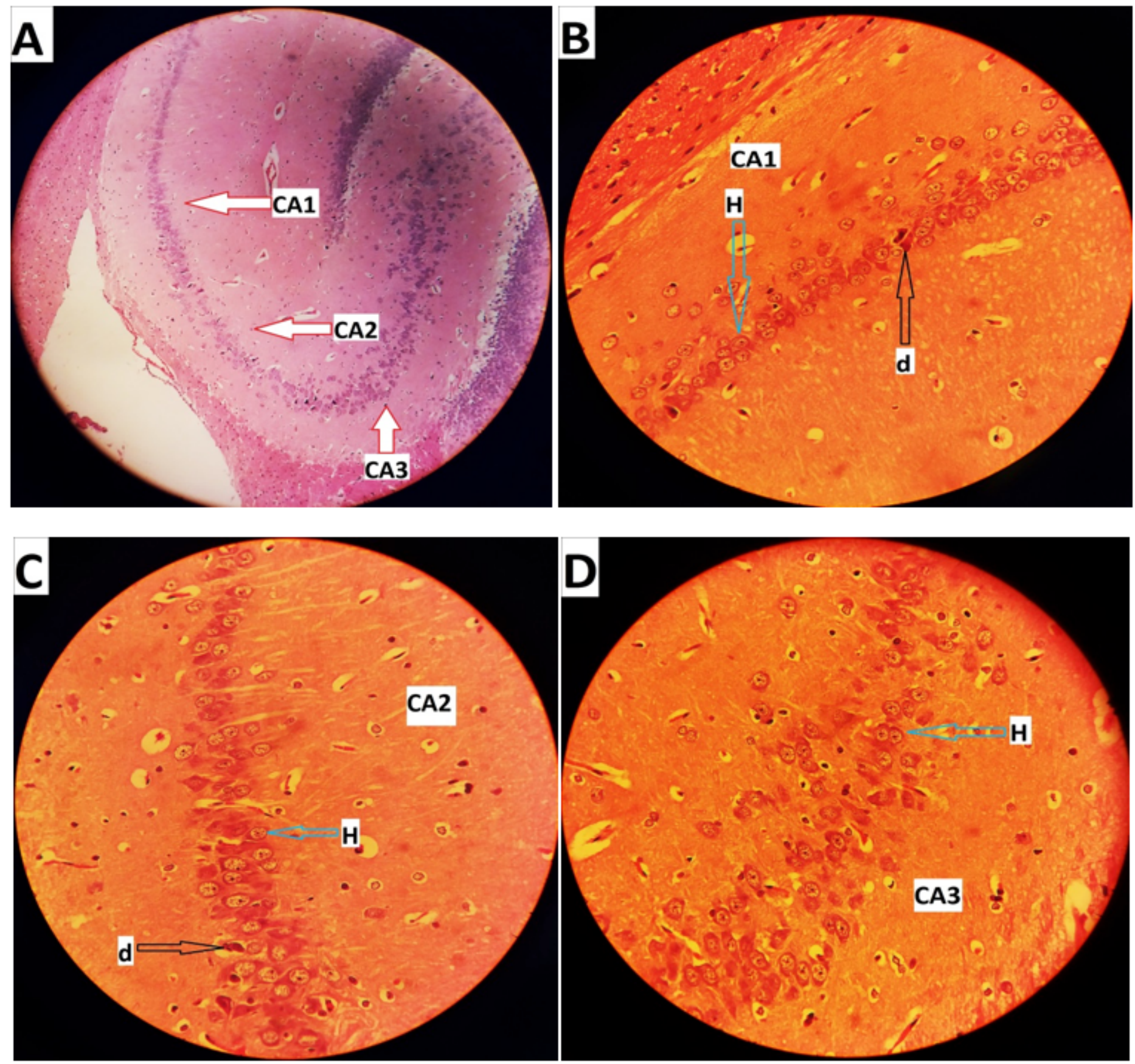

Figure 1

Longitudinal microscopic images of hippocampal tissue of control group. A (X100). B, C, D (X400). 

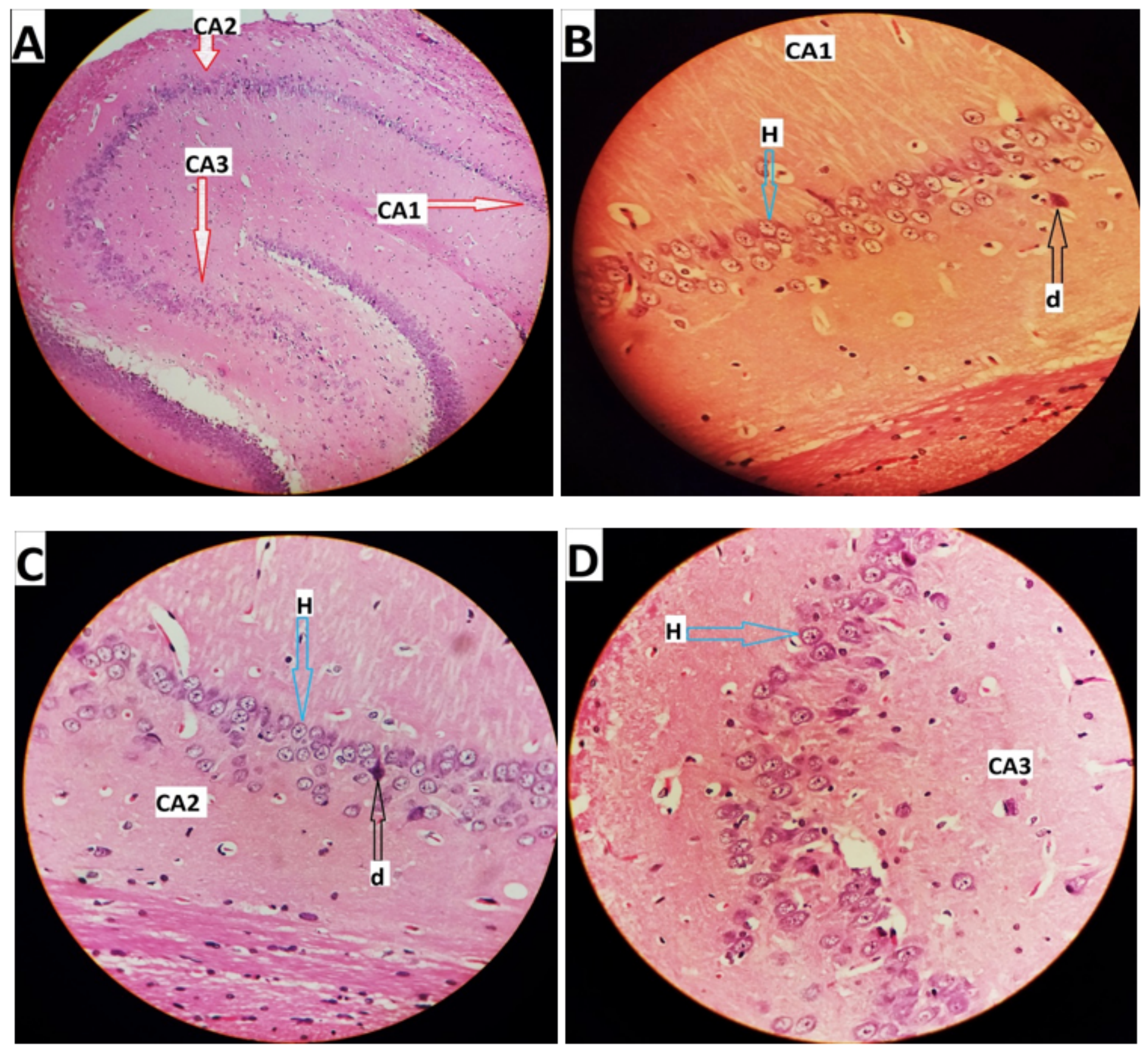

Figure 2

Longitudinal microscopic images of hippocampal tissue of Vitamin D group. A (X100). B, C, D (X400). 

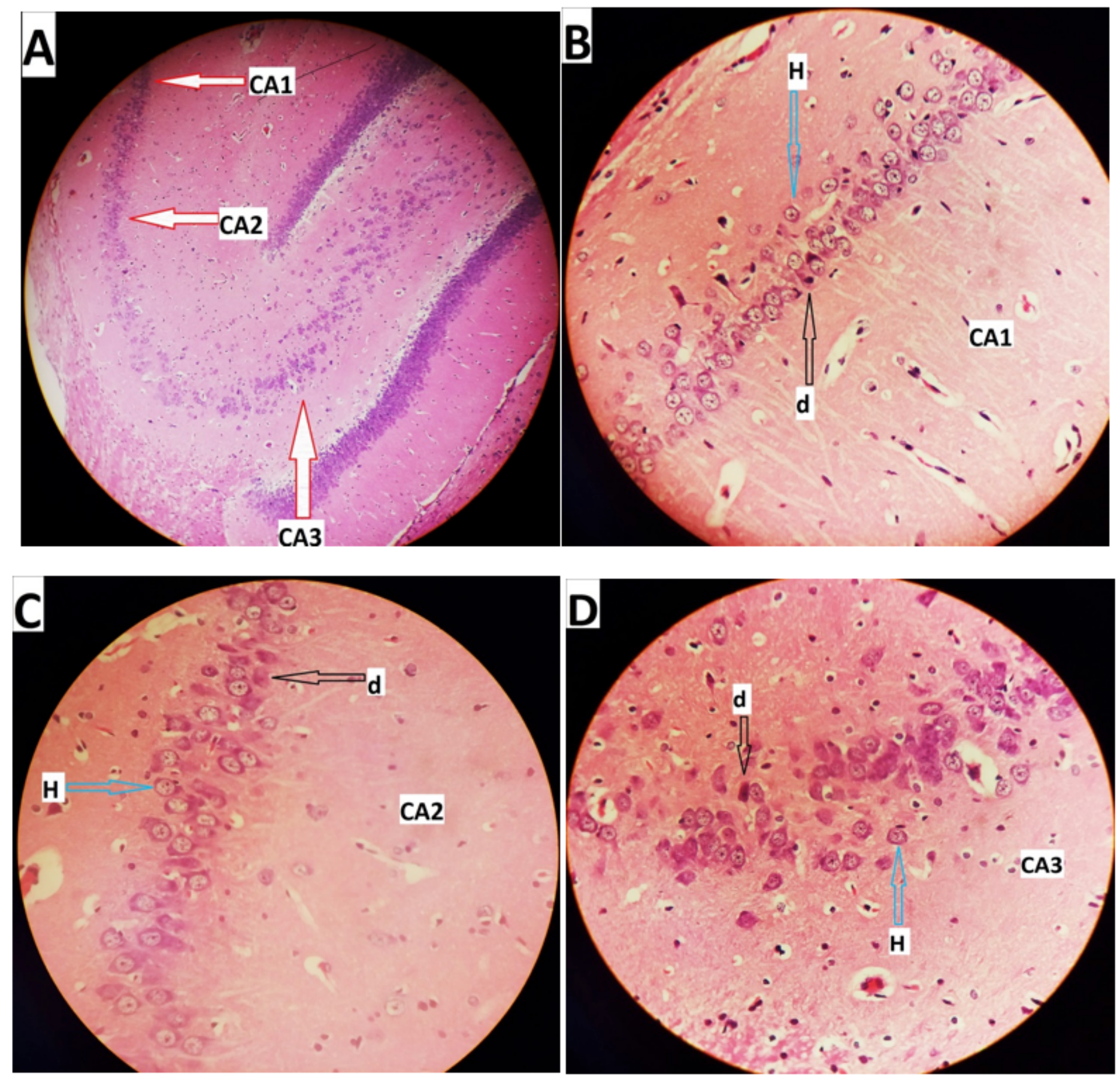

Figure 3

Longitudinal microscopic images of hippocampal tissue of SimL group. A (X100). B, C, D (X400). 

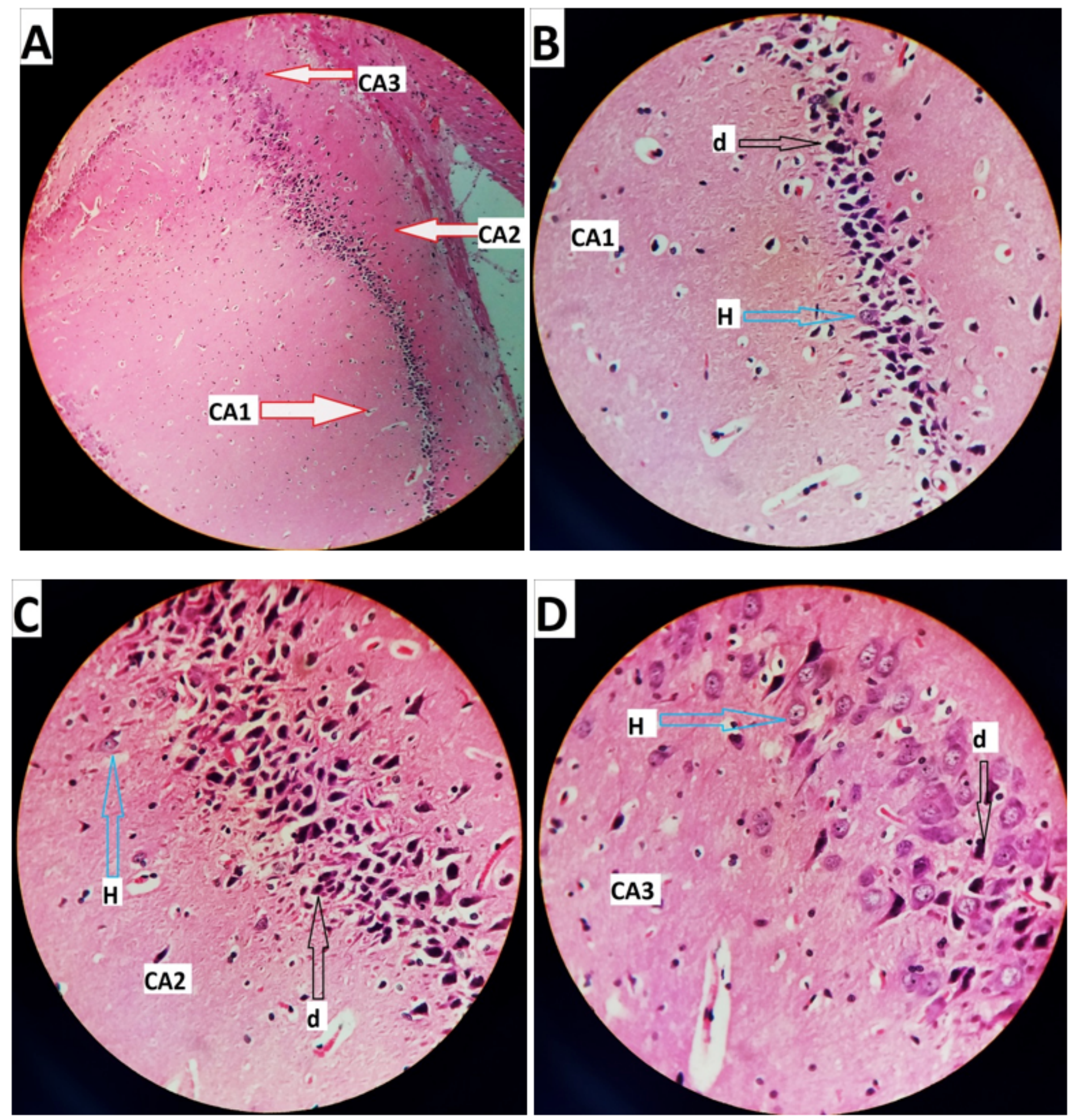

Figure 4

Longitudinal microscopic images of hippocampal tissue of SimH group. A (X100). B, C, D (X400). 

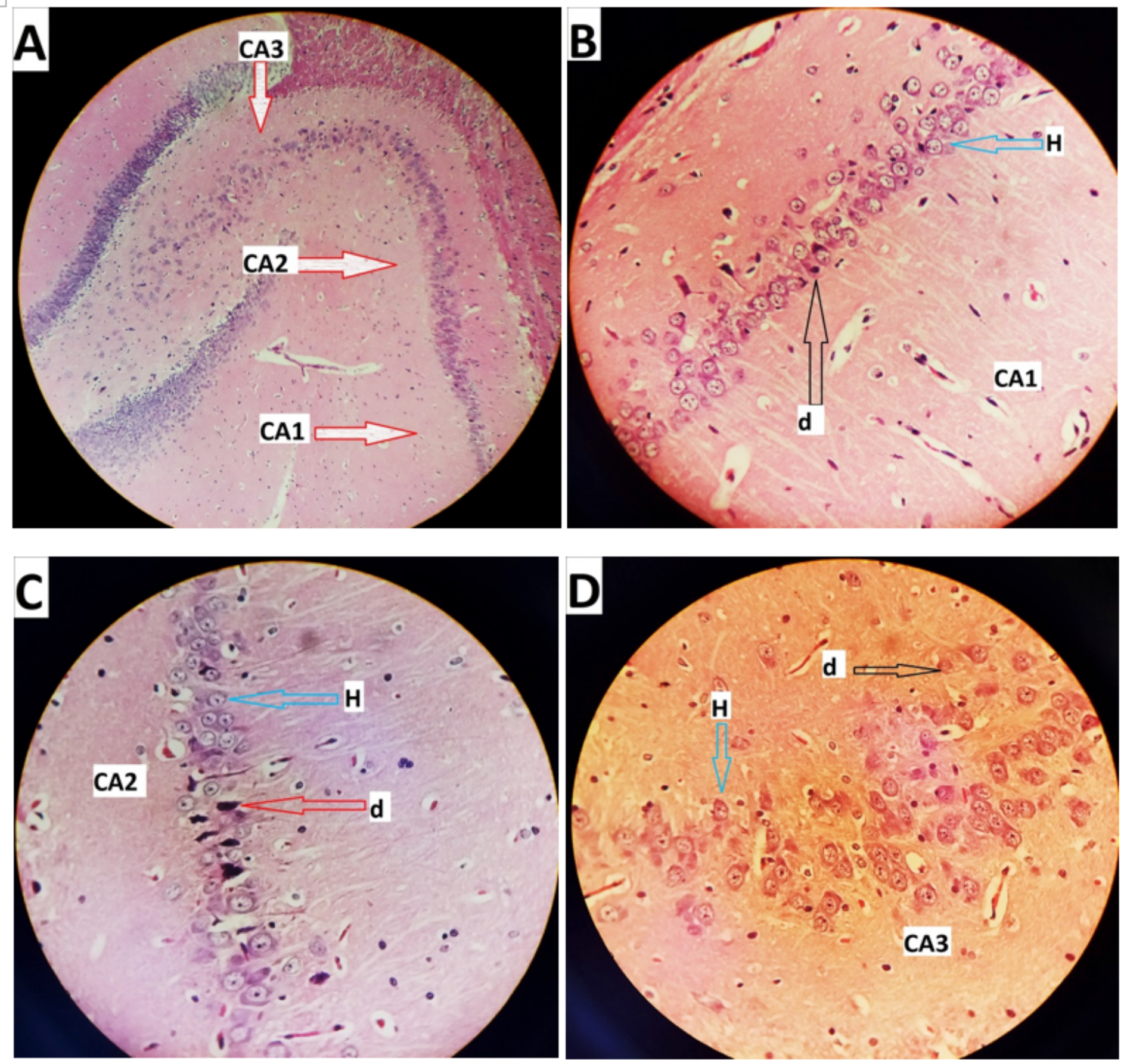

Figure 5

Longitudinal microscopic images of hippocampal tissue of SimL + VD group. A (X100). B, C, D (X400). 

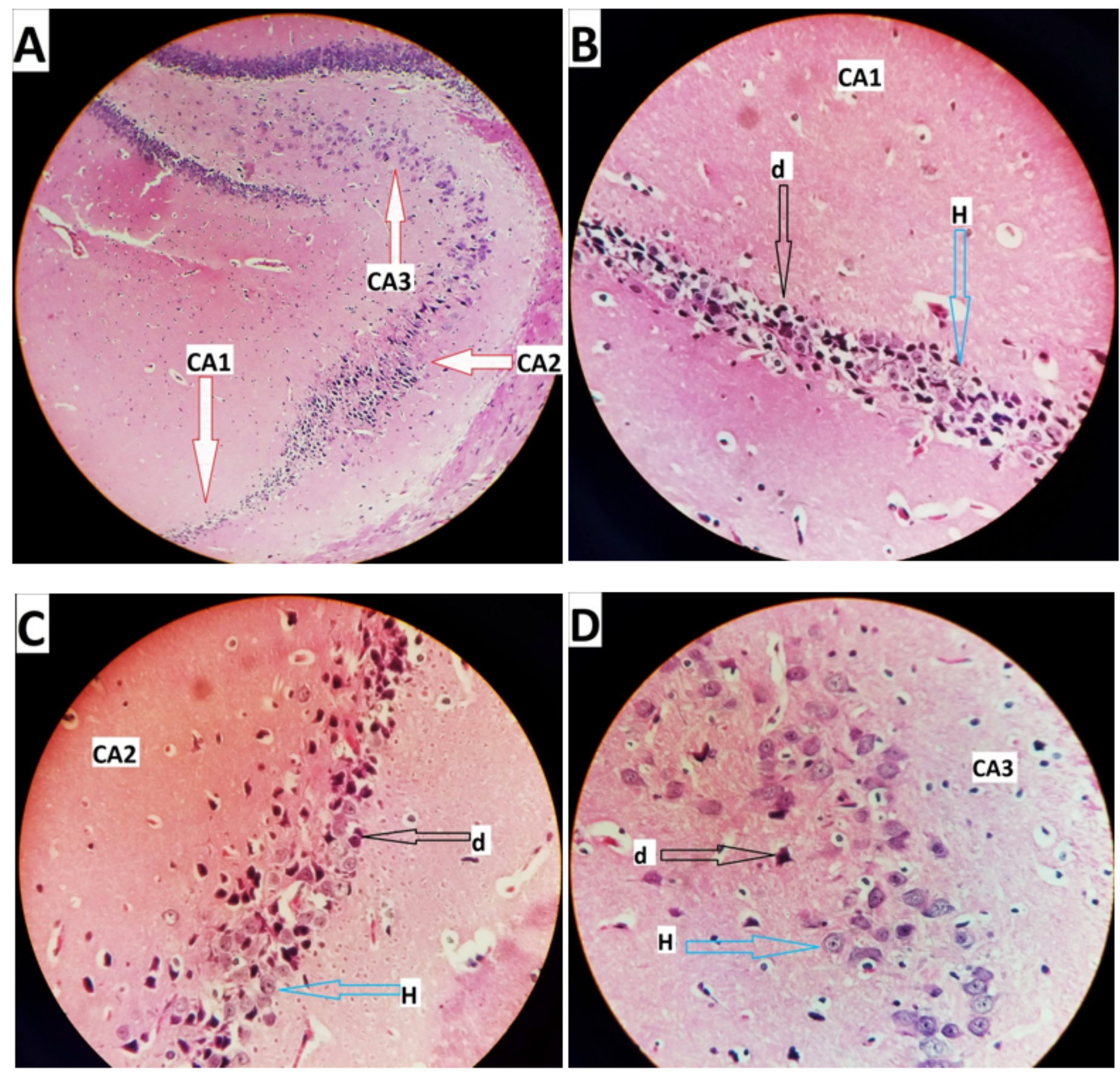

Figure 6

Longitudinal microscopic images of hippocampal tissue of SimH + VD group. A (X100). B, C, D (X400). The blue arrow with the $\mathrm{H}$ tag indicates a healthy cell in all images, and the black arrow with the $\mathrm{D}$ tag indicates a degenerate cell. 